\title{
O TRABALHO COM IMAGENS NA EXPLORAÇÃO DE TEXTOS NARRATIVOS EM AULAS DE LÍNGUA INGLESA NA ESCOLA PÚBLICA
}

Working with images as exploring narrative texts in English Language Classes of a public school

Trabajando con imágenes en la exploración de textos narrativos en clases de lengua inglesa en la escuela pública

Miliane Moreira Cardoso Vieira ${ }^{1}$, João Gomes dos Santos Filho², Jaiara Martins Aguiar Monteiro ${ }^{3}$.

${ }^{1}$ Docente do Curso de Graduação em Letras - Língua Inglesa e Literaturas, Universidade Federal do Tocantins, Araguaína, Brasil.

${ }^{2}$ Graduando do Curso de Graduação em Letras - Língua Inglesa e Literaturas, Universidade Federal do Tocantins, Araguaína, Brasil.

${ }^{3}$ Professora da Educação Básica, Secretaria de Estado da Educação, Juventude e Esportes do Tocantins - SEDUC, Araguaína, Brasil.

Artigo recebido em 01/03/2020 aprovado em 09/04/2020 publicado em 18/04/2020.

\section{INTRODUÇÃO}

Este trabalho se trata de um relato de experiência vivenciado no segundo semestre do ano de 2019, enquanto residente do Programa Residência Pedagógica (PRP), no Subprojeto de Letras - Língua Inglesa, promovido pela Coordenação de Aperfeiçoamento de Pessoal de Nível Superior Capes, conforme o Edital CAPES n06/2018, com a participação da Universidade Federal do Tocantins (UFT) e da Secretaria de Estado da Educação, Juventude e Esportes do Tocantins (SEDUC).

O desenvolvimento das atividades partiu da reflexão que ensinar uma nova língua é um alvo desafiador àqueles que se dispõem a fazê-lo, e as circunstâncias que fazem a realidade da escola pública intensificam as dificuldades ocorrentes no processo de ensino.

É de conhecimento geral que com o avançar da globalização, e pela popularização do acesso à rede de internet, os limites territoriais e a distância física deixaram de obstar o acesso a novos povos, culturas e valores, e assim se faz importante a prestação de um serviço educacional o qual atenda às necessidades que emergem das mudanças na sociedade.

Durante a formação superior, o docente em pré-serviço deve se atentar a cumprir os objetivos da área à qual está associado. De modo a atendê-los, a docência carece de proceder com a constante revisão de práticas, a partir das deficiências advindas da formação em LE em seus aspectos linguísticos e pedagógicos. Conforme explanado nas orientações educacionais complementares aos Parâmetros Curriculares Nacionais (PCN+) (BRASIL, 2002), o professor adquire um novo papel de não somente transmissor de conhecimento, mas de orientador da aprendizagem.

Portanto, em consideração ao exposto em tela, incumbe-se ao docente de Língua Estrangeira (LE) facilitar o acesso ao conhecimento, ampliando as possibilidades de acesso a outras pessoas e a outras culturas e informações, de modo a fazer o 
estudo de LE, sobretudo de Língua Inglesa (LI), mais acessível e atrativo.

\section{METODOLOGIAS E MATERIAIS}

Inicialmente, será tratada a experiência de se planejar as aulas às turmas do Ensino Médio, bem como será abordado os materiais disponíveis na unidade escolar. Será tratada também a forma que a gestão educacional orienta a construção dos planos de ensino. Em seguida, será apresentada a proposta de atividade trabalhada em uma turma do $3^{\circ}$ Ano do Ensino Médio da escola-campo.

Durante o período de imersão na unidade escolar, vislumbrou-se construir as propostas pedagógicas com amparo nos documentos oficiais e em consonância com o documento referencial para a elaboração dos planos de ensino ${ }^{1}$, o qual é determinado pela SEDUC. Esse documento lista os conteúdos obrigatórios no ensino de todas as disciplinas ministradas nas escolas da rede estadual de ensino.

Durante o segundo semestre do ano de 2019, o enfoque do PRP de LI esteve nas turmas do Ensino Médio, cujo documento referencial distribui em lista os conteúdos obrigatórios por tópicos gramaticais ao longo dos três anos de duração da etapa escolar, conforme exposto em tabela a seguir, extraída do documento referencial da SEDUC (p. 92-93).

Conforme exposto na Tabela 01 , a orientação conduz o professor a planejar as suas aulas a partir dos tópicos gramaticais previstos para o bimestre, o que leva à próxima indagação: Como ministrar os conteúdos a partir dos recursos disponíveis?

Dentre os recursos disponíveis para trabalho em sala, havia livros didáticos em quantidade suficiente para atender a todos os alunos da turma, mas não foi feito seu uso devido a circunstâncias que dificultavam fazê-lo, tais como a incompatibilidade

${ }^{1}$ (TOCANTINS, 2018)

DOI: http://dx.doi.org/10.20873/uftsupl2020-8544 de conteúdos entre o livro didático e os tópicos gramaticais do referencial da SEDUC. Além disso, o nível linguístico dos textos no livro estava muito avançado em comparação ao nível linguístico da turma.

Tabela 01. Lista vigente de conteúdos mínimos obrigatórios de LI no Ensino Médio na rede estadual de ensino do Tocantins no segundo semestre de 2019.

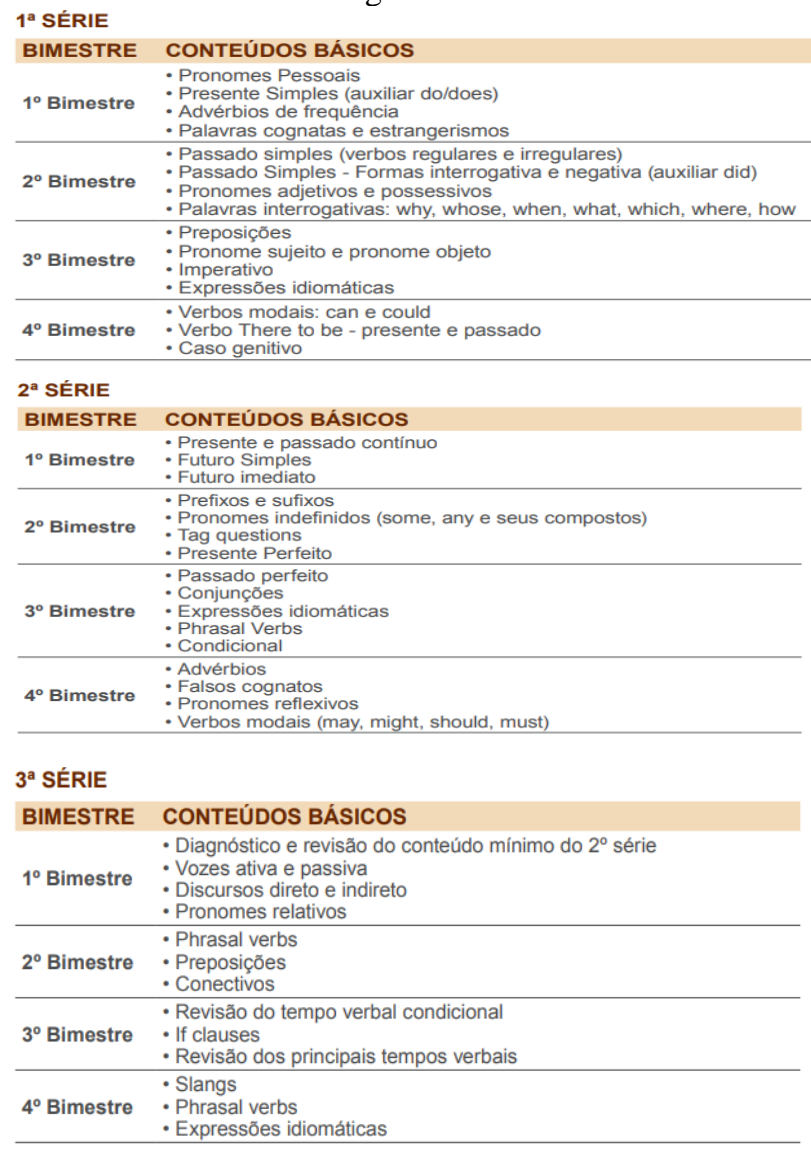

Como alternativa, de modo a minimizar a resistência por parte dos alunos, foi proposta uma atividade com um texto narrativo, com o objetivo de ensinar Phrasal Verbs a partir do uso de imagens e gestos físicos.

O método de ensino adotado para essa aula dialoga com a Abordagem Direta, a qual é descrita por Leffa (1988) como um método de ensino de língua estrangeira (qualificada como L2) o qual defende que a L2 se aprende pela L2, isto é, aprender a língua por meio de sua própria estrutura, sem recorrer à tradução. Contudo, cabe ressalvar que na educação básica, a tradução acaba sendo alvo de questionamentos, mas Leffa (op. cit.) pontua que isso

Revista Desafios - v. 7, n. Supl. RP-UFT, 2020 
se dá devido às próprias deficiências na formação linguística do professor, o que compromete a formação linguística de seus alunos.

O texto trabalhado foi adaptado de um plano de aula encontrado em uma página da internet ${ }^{2}$, cuja versão, titulada como I am a morning person!, segue abaixo.

The alarm goes off at 6 a.m., I wake up and lean over, and turn off the alarm. I get up quickly and go down to the kitchen. I have a quick breakfast and then I go to the bathroom. In the shower, I sing a song. Then I go back to the bedroom, and I dress up. After I'm done, I take my bag and set off to work. When I get to work, I walk in the class and say: Good morning, guys! (versão do texto de Clanfield [2003])

Conforme exposto, o texto acima é uma narração com eventos sequenciados. Em cada evento é utilizado uma imagem extraída da internet impressa em papel cartão, conforme exemplificado na figura a seguir.

Figura 1 Flashcards impressos em ambas as faces. Na face frontal, a imagem é exibida aos alunos, e no verso fica o evento escrito para leitura pelo professor.
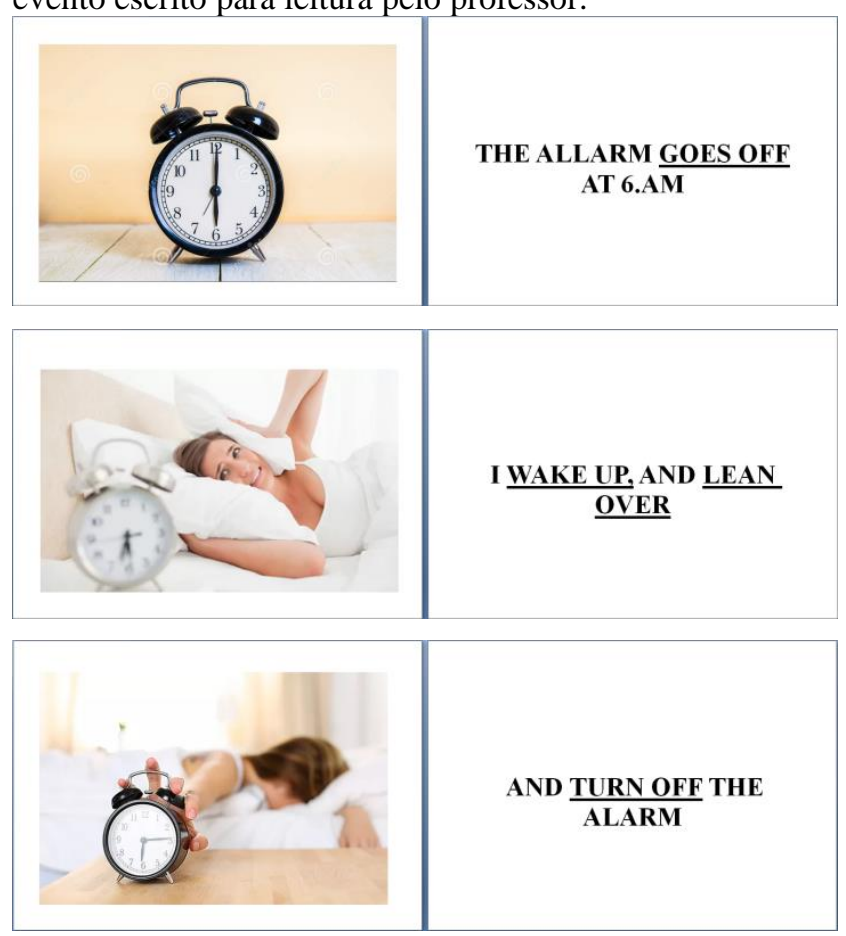

A escolha da atividade foi pensada a partir da presença de eventos que confundem os alunos, como

2 (CLANDFIELD, 2003) a diferenciação entre wake up e get up, e teve como objetivo trabalhar a função de preposições específicas como up, down, back e in, abrindo a possibilidade de discutir outras preposições essenciais para a compreensão dos discursos em LI.

$\mathrm{Na}$ etapa inicial da aula os alunos não recebem a versão escrita do texto, devendo então estar atentos à performance oral e corporal do professor. A aula é executada na seguinte sequência: 1) O professor exibe a imagem correspondente ao evento, lê-lo em voz alta e o gesticula para os alunos;

2) O primeiro passo é repetido mais de uma vez, em uma cadência que possibilite aos alunos entenderem o que ocorre no evento.

3) Ao constatar que houve essa compreensão, o professor pede aos alunos para repetir em voz alta o que eles ouviram;

4) Após performar o texto, entrega a versão escrita para conhecimento dos alunos, e dá sequência à etapa de discussão do texto.

\section{RESULTADOS E DISCUSSÃO}

A atividade ministrada na turma foi bem recebida e aproveitada pelos alunos, pois o acesso à imagem, a gesticulação e as repetições das frases alcançou a compreensão do conteúdo da aula, e o estímulo à repetição em voz alta foi o momento em que a oralidade pode ser trabalhada em sala de aula. Leffa (1988, p. 06) explana que "o aluno é primeiro exposto aos 'fatos' da língua para mais tarde chegar a sua sistematização.” Assim, os fatos da língua são as situações expostas aos alunos (vide Fig. 01) e a partir delas o aluno decodifica o sentido do texto, e assim o código lhe atribuiu um significado.

Nessa aula, foram exploradas somente as habilidades de compreensão oral e de fala, apesar de haver apontamentos que defendem que a mera repetição de palavras não configura por si só a exploração da habilidade da fala (OLIVEIRA, 2015). Contudo, a atividade dá abertura para exploração de 
outras habilidades, como a produção textual e o desenvolvimento criativo. Por exemplo, pode ser fornecido aos alunos outro pequeno texto narrativo para que eles mesmos pesquisem por imagens na internet para reconstituir os fatos constantes no texto.

Em uma situação mais avançada de letramento linguístico, uma situação comum pode ser apresentada para que os alunos criem em grupos suas próprias narrativas, respeitando assim as aprendizagens essenciais determinadas pela Base Nacional Comum Curricular do Ensino Médio (BNCC-EM) (BRASIL, 2017) e aludindo à exploração de habilidades e desenvolvimento de competências previsto no $\mathrm{PCN}+$.

Na vida escolar, no mundo social e do trabalho o jovem deverá confrontar-se com desafios que só poderão ser resolvidos no âmbito prático mediante o acesso à informação e à mobilização seletiva de competências e habilidades apropriadas (aprender a conhecer e aprender a fazer). (BRASIL, 2002, p. 94)

\section{CONCLUSÃO}

Considerando o cenário que forma a educação básica, conclui-se que o trabalho desenvolvido na escola-campo foi gratificante, por proporcionar a devida imersão do professor em préserviço, na figura do residente. Ao longo do período trabalhado na unidade escolar, foi vivenciada a experiência de dar aulas resumidas aos tópicos gramaticais e interpretação de texto, como já explanado nos Parâmetros Curriculares do Ensino Médio (PCN).

Atualmente, a grande maioria das escolas baseia as aulas de Língua Estrangeira no domínio do sistema formal da língua objeto, isto é, pretende-se levar o aluno a entender, falar, ler e escrever, acreditando que, a partir disso, ele será capaz de usar o novo idioma em situações reais de comunicação. Entretanto, o trabalho com as habilidades linguísticas citadas, por diferentes razões, acaba centrando-se nos preceitos da gramática normativa, destacando-se a norma culta e a modalidade escrita da língua. (BRASIL, 2000, p. 28).

DOI: http://dx.doi.org/10.20873/uftsupl2020-8544
Como já exposto anteriormente, deixar de utilizar o suporte do material didático também prejudica o desenvolvimento das aprendizagens essenciais em LI, porém não é caso de atribuir culpa aos sujeitos envolvidos na construção da educação pública, pois o próprio documento referencial da SEDUC dá margem a uma formação conteudista e descontextualizada. A aplicação do documento seguiu em vigor até a implementação da BNCC, e a SEDUC já elaborou um novo documento curricular elaborado a partir do documento nacional, cuja efetividade poderá ser discutida e avaliada em estudos futuros.

Todos os autores declararam não haver qualquer potencial conflito de interesses referente a este artigo.

\section{REFERÊNCIAS}

BRASIL. Parâmetros Curriculares Nacionais. Linguagens, Códigos e suas tecnologias. Brasília: MEC, 2000.

Ministério da Educação (MEC), Secretaria de Educação Média e Tecnológica (Semtec). PCN + Ensino médio: orientações educacionais complementares aos Parâmetros Curriculares Nacionais - Linguagens, códigos e suas tecnologias. Brasília: MEC, 2002.

Ministério da Educação (MEC). Base Nacional Comum Curricular - Ensino Médio. Brasília: MEC, 2017.

CLANDFIELD, Lindsay. Phrasal verbs: Teaching phrasal verbs using an oral text. Macmilan Publishers , 2003. [online], disponível em $<$ http://www.onestopenglish.com/skills/vocabulary/p hrasal-verbs/phrasal-verbs-teaching-phrasal-verbsusing-an-oral-text-and-personalizing-new-phrasalverbs-tips-and-activities/144984.article>. Acesso em 19 fev. 2020.

LEFFA, Vilson J. Metodologia do ensino de línguas. In BOHN, H. I.; VANDRESEN, P. Tópicos em linguística aplicada: $\mathrm{O}$ ensino de línguas estrangeiras. Florianópolis: Ed. da UFSC, 1988. [online] Disponível em <http://www.leffa.pro.br/textos/trabalhos/Metodologi a_ensino_linguas.pdf >. Acesso em $18 \mathrm{fev} .2020$.

TOCANTINS. Secretaria da Educação, Juventude e Esportes. Documento referencial para elaboração dos Planos de Ensino. Palmas: SEDUC, 2018. 